Article

\title{
Pilot Testing a Naturalistic Driving Study to Investigate Winter Maintenance Operator Fatigue during Winter Emergencies
}

\author{
Matthew C. Camden * (D), Jeffrey S. Hickman and Richard J. Hanowski \\ Virginia Tech Transportation Institute, Blacksburg, VA 24061, USA; jhickman@vtti.vt.edu (J.S.H.); \\ rhanowski@vtti.vt.edu (R.J.H.) \\ * Correspondence: mcamden@vtti.vt.edu; Tel.: +1-540-231-1503
}

Academic Editor: Garrett Mattos

Received: 15 April 2017; Accepted: 8 August 2017; Published: 14 August 2017

\begin{abstract}
Although numerous research studies have investigated the effects of fatigue in commercial motor vehicle drivers, research with winter maintenance (WM) drivers is sparse. This study pilot-tested the feasibility of evaluating WM operator fatigue during winter emergencies using naturalistic driving data. Four WM operators participated in the study and drove two instrumented snow plows for three consecutive winter months. The operators also wore an actigraph device used to measure sleep quantity. As this was a pilot study, the results were limited and only provided an estimation of what may be found in a large-scale naturalistic driving study with WM operators. Results showed the majority of safety-critical events (SCEs) occurred during the night, and approximately half of the SCEs occurred when participants were between 5 and $8 \mathrm{~h}$ into their shifts. Fatigue was identified as the critical reason in $33 \%$ of the SCEs, and drivers were found to average less sleep during winter emergencies versus winter non-emergencies. However, one participant accounted for all fatigue-related SCEs. Although data were limited to two instrumented trucks and four drivers, results support the approach of using naturalistic driving data to assess fatigue in WM operators. Future on-road research is needed to understand the relationship between fatigue and crash risk in WM operators.
\end{abstract}

Keywords: fatigue; winter road maintenance operations; naturalistic; actigraph; drowsiness; snow plow

\section{Introduction}

Research has shown that fatigue can significantly degrade driving performance through a loss of alertness and vigilance, decreased attention, increased reaction time, and an increased frequency in microsleeps [1]. These characteristics of fatigue may develop more frequently for commercial motor vehicle drivers as they experience varying work schedules, unusual work shifts (e.g., night driving), and long, monotonous driving conditions. The Large Truck Crash Causation Study conducted by the Federal Motor Carrier Safety Administration (FMCSA) reported that approximately $4 \%$ of truck crashes were primarily caused by the driver sleeping at the wheel, and 13\% involved driver fatigue as an associated factor [2]. Fatigue was the primary factor in 31\% of 182 fatal crashes investigated in 1990 by the National Transportation Safety Board [3].

Although numerous research studies have been performed on the effects of fatigue in commercial motor vehicle drivers, research with winter maintenance (WM) operators is sparse. WM operators are responsible for making roadways passable during winter storms. WM operators pre-treat roadways with de-icing material before a winter storm and use plows to remove snow and ice accumulation from the road during and after a winter storm. Recent news reports in the United States and Canada suggest 
operator fatigue may be a significant contributing factor to WM crashes [4-6]. Similar to commercial motor vehicle drivers, WM operators drive a heavy vehicle, may work long shifts (sometimes exceeding $18 \mathrm{~h}$ ) for consecutive days, and have irregular schedules. Unlike commercial drivers, WM operators are not subject to hours-of-service regulations. The lack of regulations regarding driving/working hours means WM operators are not required to take breaks and have no limits on the amount of driving/working hours. Furthermore, WM operators may be exposed to extreme temperatures, vibrations from the snow plow blade hitting pavement, reduced visibility, and dangerous roadway conditions. Thus, it is plausible WM operators have higher exposure to risk factors associated with fatigue compared to commercial motor vehicle operators.

In general, there are two types of fatigue: task-related and sleep-related fatigue. Task-related fatigue is associated with the performance of driving tasks, including the attention and focus required for safe operation [7]. For example, driving in a high-stress environment while completing work-related tasks may lead to task-related fatigue. Task-related fatigue may also result from continuing to drive in monotonous conditions over long periods of time. Sleep-related fatigue is associated with the time of day (circadian rhythms) and other sleep-related factors [7]. For example, driving after an inadequate rest period or after obtaining a poor night of sleep. Although fatigue and drowsiness are conceptually different, this paper will use the word "fatigue" hereafter to refer to a person's propensity to feel sleepy, regardless of its genesis.

As mentioned above, fatigue is associated with an increased risk of crashes and near-crashes. Fatigued drivers perform more inappropriate lane deviations and have slower steering responses [8,9], experience reductions in responses to speed changes of a lead vehicle [10], have increased speed variations [11], exhibit slower reaction times [9], experience impaired visual scanning or "tunnel vision", [8], and are at risk of falling asleep at the wheel [12,13]. Additionally, research has shown that fatigue affects some aspects of driving performance similar to alcohol consumption [14-16].

The purpose of this research was to conduct a pilot test on a naturalistic driving approach to investigate issues related to WM operator fatigue during winter emergencies. A winter emergency was defined as any storm that may produce snow and/or ice resulting in roadways becoming difficult to drive on. This effort should be viewed as a feasibility study to investigate a naturalistic driving approach in assessing fatigue in WM operators.

\section{Materials and Methods}

This study was approved by the Virginia Tech Institutional Review Board (IRB Number 12-1024).

\subsection{Participants and Setting}

Four WM operators from a mid-Atlantic state were recruited to participate in the study from 24 January to 29 April 2013. Three of the participants were male and one was female. Participants' typical shifts during winter non-emergencies began at 7:00 a.m. and ended at 4:00 p.m. These shifts usually involved drivers working as a team, with two drivers per vehicle. There were two, 12-h shifts during winter emergencies. The day shift started at 7:00 a.m. and ended at 7:00 p.m., whereas the night shift began at 7:00 p.m. and ended at 7:00 a.m. During winter emergencies, participants traveled solo for the duration of their shifts. Participants 1 and 2 performed the night shifts during winter emergencies and Participants 3 and 4 performed the day shifts.

The state Department of Transportation (DOT) provided two vehicles for use during the study. The first vehicle was a 2001 GMC C7500 $4 \times 4$ and the second was a 2001 International Tandem Model $26746 \times 4$. Both of these vehicles were large dump trucks retrofitted with winter road maintenance equipment (e.g., snow plows and de-icing material spreaders). These two vehicles were assigned to the four participants in the study (i.e., the participants did not drive another vehicle during the study). During winter non-emergencies, the vehicles were used for roadway repairs and the installation of roadside signs. During winter emergencies, the vehicles were used to pre-treat roadways before a winter storm, spread deicing material, and scrape snow and ice off roadways. The participants lived locally to their assigned snow removal routes and were assigned the same routes during the entire study. 


\subsection{Data Collection Equipment}

The data acquisition system (DAS) installed in the participants' vehicles allowed for the continuous collection of driver, vehicle, and roadway video whenever the vehicle's ignition was turned on. Previous versions of the system were used in several other on-road naturalistic driving studies [17-19]. The main DAS unit comprised of a Pentium-based computer that was mounted behind the driver seat of the truck. The DAS received and stored data from a network of sensors distributed throughout the vehicle. The sensors used in the study included an accelerometer, a yaw rate (gyro) sensor, a GPS sensor, and five video camera that covered the driver and roadway (i.e., forward roadway, backwards facing views of the left and right side of the snow plow, the driver's face, and an over-the-shoulder view of the driver, steering wheel, and dash board; see Figure 1). The video and other sensor data were stored on an external hard drive that was locked in place to prevent tampering.

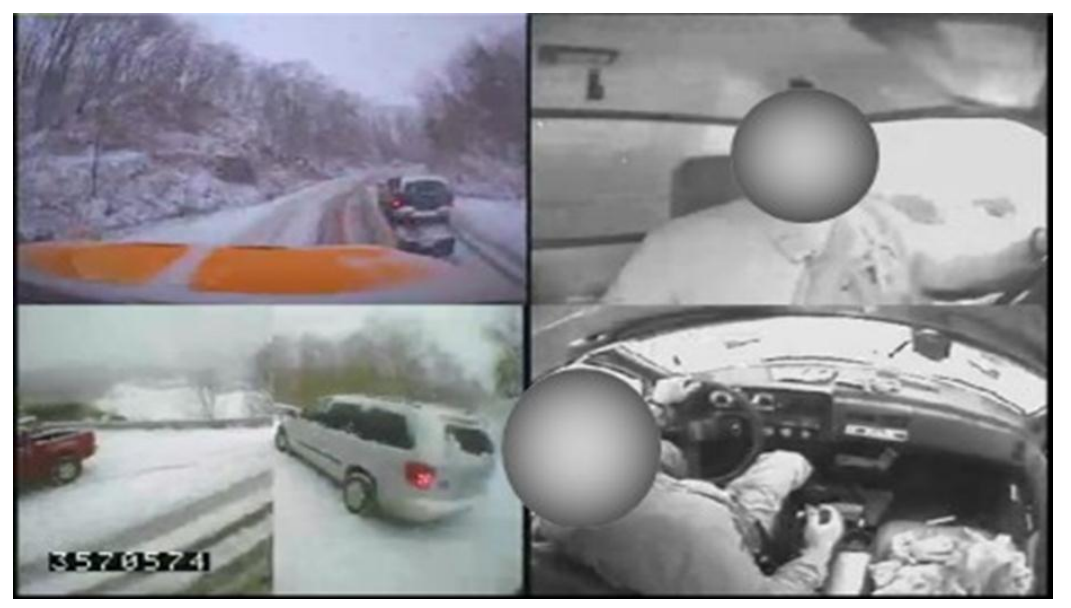

Figure 1. Five video images multiplexed into a single image.

Each participant was instructed to wear an actigraph device on the wrist of his/her non-dominant hand. The Octagonal Basic motionlogger actigraph device (Figure 2) developed by Ambulatory Monitoring, Inc. was used in this study. An actigraph unit is a "wrist watch" device that tracks activity levels to assess the wearer's sleep quantity and quality. As shown in Figure 2, the Octagonal Basic actigraph was non-invasive and worn like a wrist watch but was slightly bulkier and heavier. The participant's wrist motion was detected and recorded by the actigraph device one minute epochs.

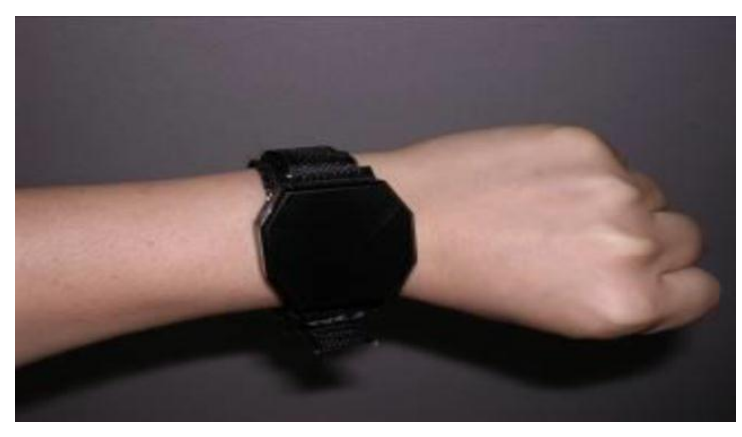

Figure 2. Ambulatory Monitoring Inc. Octagonal Basic actigraph device.

\subsection{Data Collection Procedures}

Once the study objectives were discussed with the participants and the Informed Consent Form was signed, installation of DAS components and operational checks were completed by researchers 
in 6-7 h. The DAS and data collection sensors were installed in the appropriate locations without any permanent modification using customized brackets designed individually based on mirror style, vehicle cab, or dashboard. All wiring and cables connecting the sensors to the DAS were hidden under carpeting and plastic paneling. Researchers performed operational checks to ensure all data collection equipment functioned as intended and oriented the DAS cameras to the participants' normal driving positioning. Researchers ensured the cameras were oriented to capture both participating WM operators that shared the same snow plow. These diagnostic checks and adjustments were also performed each time researchers met with the participants.

Immediately following vehicle instrumentation and prior to driving, researchers provided each participant an actigraph device to wear on his/her non-dominant wrist. Participants were asked to wear the actigraph device $24 \mathrm{~h}$ a day, seven days a week for the duration of the study. Participants were instructed to remove the actigraph device only when showering, washing dishes, swimming, or performing any other task during which the actigraph device may become submerged in water. To minimize data loss, participants were also asked to replace the device on their wrist as soon as possible after performing such activities.

Participants were instructed to perform their normal duties as a WM operator. Researchers met with each participant bi-weekly to inspect the DAS, replace hard drives with empty hard drives, and download the actigraph data. Once the hard drives were collected, the data were downloaded to a secure server. Each file on the hard drive was inspected to verify the appropriate driver was operating the instrumented vehicle. Files from non-participating drivers were deleted. If a file contained both a participating and non-participating driver, the file was manually edited to remove all instances where the non-participating driver operated the vehicle. This process of uploading hard drives and verification and inspection required approximately $5 \mathrm{~h}$. Actigraph data were reviewed to verify the participant was wearing the actigraph device as instructed. If data indicated the participant had removed the actigraph device for an extended period of time or a large aggregate sum of time, researchers reminded the participant to wear the device as much as possible with the exception of time periods when it could potentially be submerged in water.

Once participants completed three months of data collection, researchers scheduled a final meeting to collect the actigraph devices and participant contact information. The following day, each participant was mailed compensation for his/her time in the study. Compensation was $\$ 100$ per month, plus a $\$ 100$ bonus for completing the study. The DAS was then removed, which returned each vehicle to its original condition. This entire process was completed in $3 \mathrm{~h}$ for each vehicle.

\subsection{Data Reduction}

Participants' kinematic and video data were reviewed to identify safety-critical events (SCEs). An SCE occurred when there were one or more vehicles involved in a conflict and at least one of those vehicles had to perform an evasive maneuver. SCEs were classified into one of seven categories as described in Table 1. Event-threshold algorithms scanned all driving data to flag potential risky events. These algorithms scanned kinematic data to determine if a risky event may have been encountered. Risky events included instances of hard braking/acceleration (i.e., acceleration or deceleration exceeding $|0.20 \mathrm{~g}|$ ) and swerving (i.e., exceeding a wheel angle of $2^{\circ}$ while traveling at least $15 \mathrm{miles} / \mathrm{h}$ ). These thresholds were developed in prior naturalistic truck driving studies [17,19-21] and adapted for use with the WM vehicles. Flagged events were then reviewed to verify if a risky event occurred. Valid events were those where recorded dynamic motion values actually occurred and a safety-related conflict was present (i.e., an SCE). Invalid triggers were not analyzed further. Two researchers reviewed $33 \%$ of flagged events to assess reliability. Reliability between these two researchers was $99.60 \%$ agreement. All discrepancies were resolved by a third expert analyst. This validation process required approximately $1000 \mathrm{~h}$ to manually review all events. 
Table 1. Description of each type of SCE [17,19-21].

\begin{tabular}{|c|c|}
\hline SCE Type & Description \\
\hline Crash & $\begin{array}{l}\text { Any conflict with an object, either moving or fixed, at any speed (with the } \\
\text { exception of low-hanging tree branches and curbs). }\end{array}$ \\
\hline $\begin{array}{l}\text { Crash: } \\
\text { low-hanging } \\
\text { branch }\end{array}$ & $\begin{array}{l}\text { Any contact with a low-hanging tree branch at any speed. The most likely } \\
\text { cause for these events in the current study are tree branches covered with } \\
\text { snow and ice. }\end{array}$ \\
\hline $\begin{array}{l}\text { Curb strike: } \\
\text { avoidable }\end{array}$ & $\begin{array}{l}\text { The vehicle made contact with a curb. However, the driver could have } \\
\text { avoided contact with the curb if the maneuver was executed differently. }\end{array}$ \\
\hline $\begin{array}{l}\text { Curb strike: } \\
\text { unavoidable }\end{array}$ & $\begin{array}{l}\text { The vehicle made contact with a curb. However, the driver could not have } \\
\text { avoided contact with the curb if the maneuver was executed differently. } \\
\text { Unavoidable curb strikes are most likely the result of a poorly } \\
\text { designed roadway. }\end{array}$ \\
\hline Near-crash & $\begin{array}{l}\text { A situation that required a driver to perform a rapid, evasive maneuver to } \\
\text { avoid contact with any other vehicle, object, pedestrian, cyclist, or animal. } \\
\text { The most common evasive maneuvers involve a hard brake or swerve. }\end{array}$ \\
\hline $\begin{array}{l}\text { Crash-relevant } \\
\text { conflict }\end{array}$ & $\begin{array}{l}\text { A situation that required someone to perform a crash-avoidance maneuver. } \\
\text { The maneuver was less severe than a rapid evasive maneuver found in a } \\
\text { near-crash but more severe than a normal maneuver. }\end{array}$ \\
\hline Illegal maneuver & A situation where a driver performed any act that was illegal. \\
\hline
\end{tabular}

Once all SCEs were validated, the expert analyst used a data directory to reduce and analyze all SCEs. This data directory has been used and validated in previous on-road studies [17,19-21]. Example variables in the data directory included pre-event movement, critical reason for the conflict, distraction(s), road condition, weather condition, observer rating of drowsiness (ORD), and if the event occurred during a winter emergency. This study used the same ORD procedures as described by Wierwille and Ellsworth [22]. Wierwille and Ellsworth [22] demonstrated that ORD was highly correlated with measures of eye closure. Please refer to Wierwille and Ellsworth [22] for additional information on ORD. The expert analyst reviewed $60 \mathrm{~s}$ of video prior to the SCEs and rated the drivers' level of drowsiness/fatigue on a continuous scale from 0 to 100. An ORD of 0 referred to a driver that was wide awake with no signs of fatigue. For example, a driver with an ORD of 0 had normal facial expressions, normal rates of eye blinks, and short, frequent glances. An ORD of 50 indicated moderate drowsiness. A driver with an ORD of 50 may have rubbed the face or eyes, moved restlessly in the seat, exhibited decreased facial tone, and/or had slower eye blinks. An ORD of 100 referred to a driver was completely asleep. Applying the data directory and performing an ORD for all SCEs required approximately $24 \mathrm{~h}$ labor.

Actigraph data were used to measure sleep quantity for the participating drivers. Several steps were taken to prepare the actigraph data for analysis. For each actigraph file, a researcher converted data into minute-by-minute files, identified and marked any "bad data" episodes (i.e., 20 consecutive minutes of zero movement as there is minor activity even in sleep), and ran the proprietary "Action4" algorithm to identify sleep periods. In general, the "Action4" algorithm scanned the participant's activity levels to identify episodes where the participant was likely to be asleep. All "bad data" minutes were excluded from the algorithm to identify sleep periods. The entire process to upload, convert, identify "bad data", and apply the algorithm required approximately $10 \mathrm{~h}$.

All raw data collected during this project are not publically available and restricted by Virginia Tech's IRB due to the personally identifying information contained in the video recordings. 


\section{Results}

Given this was a feasibility study, results are limited to descriptive statistics. The results below are included to provide an estimation of what may be found in a large-scale naturalistic study with WM operators.

\subsection{Naturalistic Driving Results}

The naturalistic driving data resulted in 380 gigabytes of data. The two instrumented trucks were dispatched a total of 39 winter emergencies days (not mutually exclusive as both trucks may have been dispatched on the same day). A total of 20 inches of snow fell during these winter emergencies including: five storms that produced less than 1 inch of snow and ice, three storms that produced between 1 and 3 inches of snow and ice, and three storms that produced more than 3 inches of snow and ice. The GMC truck was dispatched for 24 days, and the International Tandem truck was dispatched for 15 days (limited number of days due to vehicle maintenance). Approximately $369 \mathrm{~h}$ of video and sensor data were collected during the study; $339 \mathrm{~h}$ were collected during winter emergencies and $30 \mathrm{~h}$ were collected during normal operations during the winter (e.g., mostly travel to and from different work sites, no plow was attached to the truck). These data included a total of 9185 acceleration/deceleration events and 16,840 swerve events.

A total of 92 SCEs were identified. Of these 92 SCEs, 9 were due to acceleration/deceleration, and 83 were due to swerving. Participant 1 accounted for $54.5 \%$ of all SCEs. Three of the 92 SCEs were crashes, 16 were collisions with snow/ice covered low-hanging branches, 3 were avoidable curb strikes, 21 were near-crashes, and 49 were crash-relevant conflicts. Nearly all of the SCEs (85 SCEs) occurred on a free-flowing, non-divided two lane road. Only seven SCEs occurred on a divided four lane road with limited traffic. Additionally, 90 of the 92 SCEs occurred during a winter emergency. The high percentage of SCEs occurring during winter emergencies was likely the result of the limited amount of data captured during winter non-emergencies. Figure 3 shows the percentage of SCEs by the hour of the day. As shown, the majority of SCEs (56.5\%) occurred between 12:00 a.m. and 6:00 a.m. Figure 4 shows approximately half of the SCEs occurred when participants were between five and eight $h$ into their shifts.

In terms of fatigue, participants were considered fatigued if the ORD was equal to or greater than 40 [17]. Participants were identified as fatigued in 33 out of the 92 SCEs (35.87\%). The data analyst was unable to perform the ORD for Participant 2. Participant 2's eyes were not clearly visible. However, there were no behavioral signs that indicated Participant 2 was fatigued. Table 2 shows Participant 1 accounted for all the fatigue-related SCEs. The most frequently coded critical reason in the SCEs was drowsiness / fatigue/sleep ( $28.3 \%$ of all SCEs). The critical reason was described as the primary reason the SCE occurred. In other words, if the critical reason was removed, the SCE would be prevented or mitigated from occurring [23]. Table 2 shows the SCEs by participant.

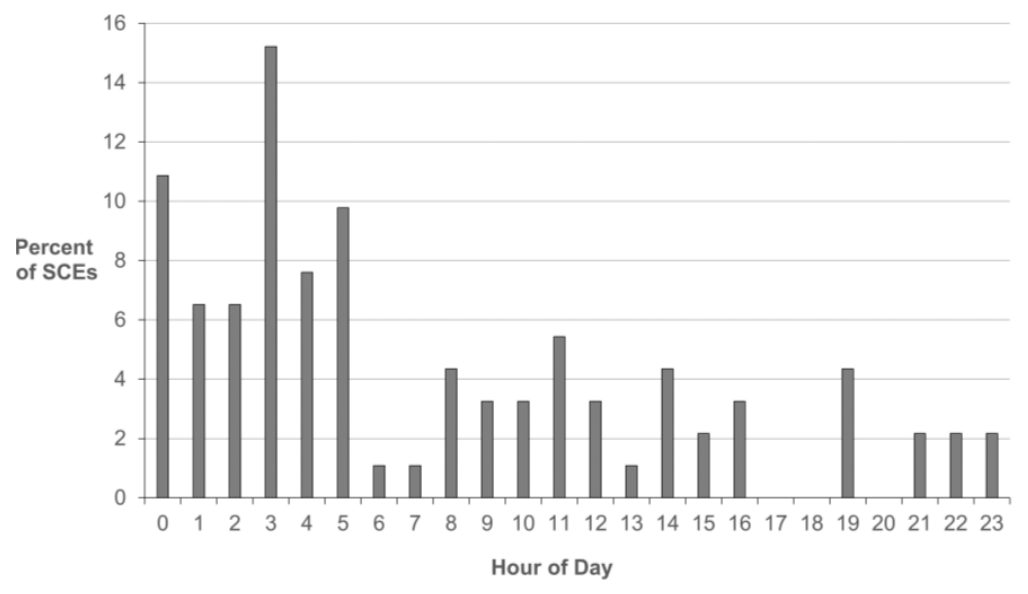

Figure 3. Percent of safety-critical events (SCEs) by hour of day. 


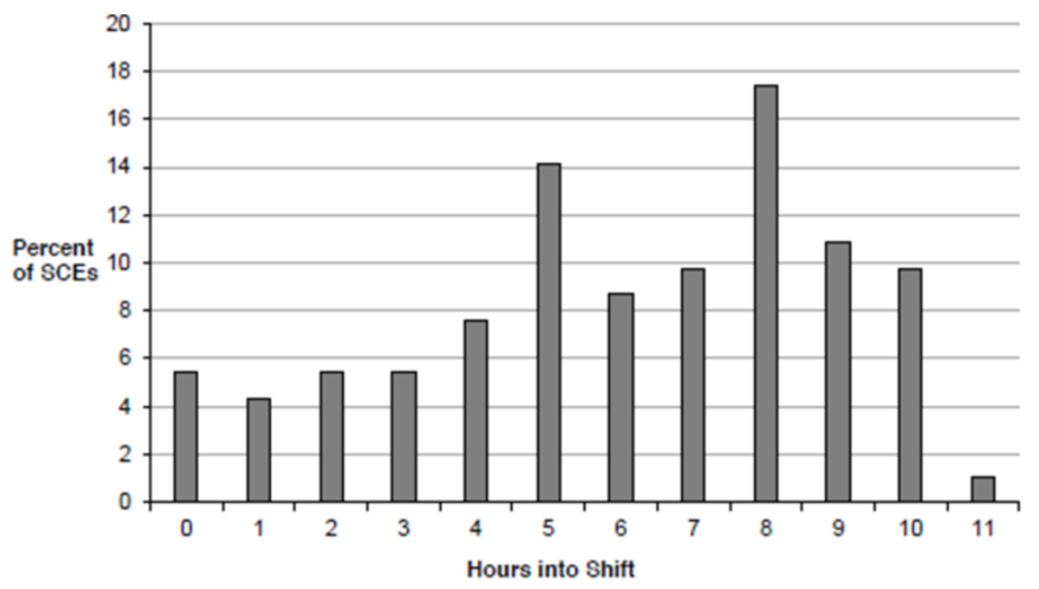

Figure 4. Percent of SCEs by number of hours into shift.

Table 2. Summary of safety-critical events (SCEs) by participant.

\begin{tabular}{cccc}
\hline Participant & Shift & Total SCEs & Total Number of SCEs with Fatigue \\
\hline 1 & Night & 52 & 33 \\
2 & Night & 12 & N/A \\
3 & Day & 16 & 0 \\
4 & Day & 12 & 0 \\
\hline
\end{tabular}

\subsection{Actigraph Results}

Although each participant was instructed to wear the actigraph device at all times (with the exception of when the device may become submerged in water), there were instances when the actigraph was removed for an extended period of time. For example, the actigraph band broke on three devices; thus, the participants could not wear the actigraph until it was replaced. Furthermore, the actigraph recorded false readings in some situations (e.g., the actigraph would record zero movement when pressed against another object for an extended period of time). Table 3 shows the amount of actigraph data collected in the study. The actigraph data collection resulted in 54.2 megabytes of data.

Table 3. Summary of actigraph data collected.

\begin{tabular}{cccc}
\hline Participant & Total Minutes Worn & Total Bad Minutes & Percent Bad Minutes \\
\hline 1 & 128,729 & 19,123 & $14.86 \%$ \\
2 & 129,065 & 15,244 & $11.81 \%$ \\
3 & 129,029 & 12,289 & $9.52 \%$ \\
4 & 130,044 & 6956 & $5.35 \%$ \\
Total & 516,867 & 53,612 & $10.37 \%$ \\
\hline
\end{tabular}

Table 4 shows the average amount of sleep (defined as the total amount of sleep obtained) for each participant during the study. As shown in Table 4, participants averaged $8.71 \mathrm{~h}$ of sleep per day $(N=343$ days; $S D=2.41 \mathrm{~h}), 8.98 \mathrm{~h}$ of sleep per day during winter non-emergencies $(N=256$ days; $S D=1.56 \mathrm{~h}), 7.87$ $\mathrm{h}$ of sleep $24 \mathrm{~h}$ prior to a winter emergency $(N=34$ days; $S D=1.60 \mathrm{~h}), 8.31 \mathrm{~h}$ of sleep during consecutive winter emergency shifts $(N=37$ days; $S D=1.43 \mathrm{~h})$, and $7.30 \mathrm{~h}$ of sleep $24 \mathrm{~h}$ prior to an SCE $(N=92$ days; $S D=1.89 \mathrm{~h}$ ). However, Participant 1 averaged only $6.31 \mathrm{~h}$ of sleep $24 \mathrm{~h}$ prior to a winter emergency and only $4.55 \mathrm{~h}$ of sleep $24 \mathrm{~h}$ prior to a SCE (compared to an overall average of $8.05 \mathrm{~h}$ of sleep). 
Table 4. Summary of drivers' sleep (in hour).

\begin{tabular}{cccccc}
\hline Participant & $\begin{array}{c}\text { Daily } \\
\text { Sleep }\end{array}$ & $\begin{array}{c}\text { Daily Sleep } \\
\text { during Winter } \\
\text { Non-Emergency }\end{array}$ & $\begin{array}{c}\text { Sleep 24 H Prior } \\
\text { to a Winter } \\
\text { Emergency }\end{array}$ & $\begin{array}{c}\text { Sleep during } \\
\text { Consecutive Winter } \\
\text { Emergency Shifts }\end{array}$ & $\begin{array}{c}\text { Sleep 24 H } \\
\text { Prior to SCE }\end{array}$ \\
\hline 1 & 8.05 & 8.63 & 6.31 & 7.48 & 4.55 \\
2 & 10.04 & 10.66 & 8.58 & 8.71 & 8.83 \\
3 & 8.12 & 8.10 & 8.26 & 8.32 & 8.02 \\
4 & 8.64 & 8.53 & 8.31 & 8.73 & 7.81 \\
\hline Average & 8.71 & 8.98 & 7.87 & 8.31 & 7.30 \\
\hline
\end{tabular}

\section{Discussion}

In this pilot test, numerous data were collected from vehicle sensors in two instrumented snow plows driven by four WM operators. Although the instrumented vehicle data were useful in demonstrating the feasibility of collecting naturalistic data in WM vehicles, it was not possible to make generalizations based on such a small sample.

Previous research found fatigue-related commercial motor vehicle crashes were prevalent given drivers' extended work hours and irregular shifts. Among the four drivers in this project, fatigue was coded as the critical reason in $28.3 \%$ of the SCEs. This is consistent with the results obtained by Knipling and Wang [3]. However, a closer inspection of the data revealed that one driver accounted for all of the fatigue-related SCEs. In other words, three of the four WM operators did not have any fatigue-related SCEs, and one WM operator was moderately drowsy or greater in the majority of his/her SCEs (63.5\%). It is possible the data reduction methodology missed some fatigue-related SCEs. For example, a fatigued driver may not have exceeded the event thresholds, but another vehicle was forced to perform an evasive maneuver to avoid contact with the participant. However, the event-thresholds were low enough that these types of events were unlikely to be missed.

Another interesting trend was a possible time-on-task effect. The percent of SCEs increased as the number of hours into a shift increased (and then sharply decreased at the end of the shift). In other words, more SCEs occurred when a driver had been on duty for nine $\mathrm{h}$ compared to when a driver had been on duty for two $\mathrm{h}$. This may suggest WM operators became more fatigued the longer their shifts lasted. However, it is not possible to make any conclusions based on a sample size of four and the lack of exposure data (i.e., how often WM operators drove beyond $9 \mathrm{~h}$ ).

The actigraph data provided additional insight into possible explanations for the results obtained by the vehicle sensors. Previous research demonstrated that extended time awake, an inadequate amount of sleep, and time of day all increase fatigue among drivers [24]. Participant 1 averaged approximately two $h$ of sleep less per night during the $24 \mathrm{~h}$ prior to the start of a winter emergency compared to the amount of sleep obtained during winter non-emergencies. Furthermore, Participant 1 averaged approximately four $\mathrm{h}$ less sleep during the $24 \mathrm{~h}$ prior to an SCE compared to the amount of sleep obtained during winter non-emergencies. Most people need approximately eight $\mathrm{h}$ of sleep per night to feel well rested [25]. Thus, Participant 1 experienced an increased risk of fatigue due to extended time awake and an inadequate amount of sleep [24]. Additionally, Participant 1 worked the night shift during winter emergencies but the day shift during winter non-emergencies. The highest quality sleep occurs when sleep is coordinated with the body's normal circadian rhythm [26]; switching between daytime and nighttime shifts disrupt the body's circadian rhythm and decreasing sleep quantity and quality [27]. Thus, switching between day and night shifts disrupted Participant 1's normal circadian rhythm. This may have made it challenging to obtain a full sleep period. Participant 2 also experienced circadian rhythm disruption but was able average over $8 \mathrm{~h}$ of sleep each day. Thus, circadian rhythm disruption coupled with poor sleep hygiene likely explains why Participant 1 accounted for all the fatigue-related SCEs. Future studies should further investigate the interaction between circadian rhythm disruption coupled with poor sleep hygiene. Please note that the proprietary nature of the "Action4" algorithm limits researchers' ability to independently evaluate the accuracy of the algorithm. 
Finally, the algorithms used in this pilot study identified approximately 25,000 SCEs. Event thresholds were purposively set low to limit missed events. These thresholds were based on naturalistic driving studies with large trucks. However, snow plows experienced much more horizontal and lateral acceleration due to the snow plow blade scraping the snow and ice off the roadway, which resulted in very large numbers of false positive SCE identifications by the flagging algorithm". Thus, future naturalistic driving studies with snow plows should reassess event threshold limits and algorithms and include manual data reduction of flagged safety events.

\section{Conclusions}

The purpose of this research was to investigate the feasibility of studying WM operator fatigue using naturalistic driving data. Although data were limited to two trucks and four drivers, the results support a large-scale naturalistic driving approach to assess WM operator fatigue during winter emergencies. Future on-road research is needed to understand the relationship between WM operator fatigue and crash risk. This future study should include a larger number WM vehicles in states that experience significant snowfall during the winter months. Participants should wear actigraph devices to measure sleep hygiene. Daily activity registers should also be completed to validate sleep periods, record driver breaks, track medication/caffeine use, and document scheduling practices before and during winter emergencies.

Acknowledgments: This project was funded through the Clear Roads Pooled Fund \#TPF-5(218). Clear Roads had no involvement in the study design, data collection, analysis and interpretation of the data, writing of the report, or in the decision to submit the article for publication. Support from Virginia's Department of Transportation, and specifically Allen Williams, was instrumental in the project's successful completion. Additionally. Alejandra Medina-Flintsch, James Bryce, and Gerardo Flintsch provided critical support throughout the project.

Author Contributions: Matthew C. Camden and Jeffrey S. Hickman designed and performed the naturalistic driving study. Matthew C. Camden and Jeffrey S. Hickman also analyzed the data and wrote the paper. Richard J. Hanowski provided invaluable guidance, insight, and support throughout the entirety of the project.

Conflicts of Interest: The authors declare no conflict of interest. Furthermore, the funding sponsors had no role in the design of the study; in the collection, analyses, or interpretation of data; in the writing of the manuscript, and in the decision to publish the results.

\section{References}

1. Moscovitch, A.; Reimer, M.; Heslegrave, R.; Boivin, D.; Hirshkowitz, M.; Rhodes, W.; Kealey, M. Development of a North-American Fatigue Management Program for Commercial Motor Carriers: Phase II (Pilot Study) (Report No. TP 14828E); Transport Canada, Transportation Development Centre: Ottawa, ON, Canada, 2006.

2. Federal Motor Carrier Safety Administration. Report to Congress on the Large Truck Crash Causation Study (Report No. MC-R/MC-RRA); Federal Motor Carrier Safety Administration: Washington, DC, USA, 2006.

3. Knipling, R.R.; Wang, J.S. Research Note: Crashes and Fatalities Related to Driver Drowsiness/Fatigue; National Highway Traffic Safety Administration: Washington, DC, USA, 1994.

4. Morabito, N. Public TDOT Records Reveal Snow Plow Drivers Worked 60 to 80 Hours with Limited Sleep. 14 March 2016. Available online: http:/ / wjhl.com/2016/03/14/public-records-from-tdot-reveals-snowplow-drivers-worked-60-to-80-hours-without-sleep/ (accessed on 1 August 2017).

5. Smith, C. Open-ended shifts for snowplow drivers raise questions. 30 January 2017. Available online: http:/ / www.cbc.ca/news/canada/new-brunswick/snowplow-open-ended-shifts-1.3954934 (accessed on 10 February 2017).

6. Anderson, K. 5 Investigates: Fatigue, few rules surround snowplow drivers in storms. 10 February 2015. Available online: http:/ / www.wcvb.com/article/5-investigates-fatigue-few-rules-surround-snowplowdrivers-in-storms / 8216959 (accessed on 1 August 2017).

7. May, J.F.; Baldwin, C.L. Driver fatigue: The importance of identifying causal factors of fatigue when considering detection and countermeasure technologies. Transp. Res. F Traffic Psychol. Behav. 2009, 12, 218-224. [CrossRef] 
8. Barr, L.C.; Yang, C.Y.; Hanowski, R.J.; Olson, R. Assessment of Driver Drowsiness, Distraction, and Performance in a Naturalistic Setting (Report No. FMCSA-RRR-11-010); Federal Motor Carrier Safety Administration: Washington, DC, USA, 2011.

9. Philip, P.; Sagaspe, P.; Moore, N.; Taillard, J.; Charles, A.; Guilleminault, C.; Bioulac, B. Fatigue, sleep restriction and driving performance. Accid. Anal. Prev. 2005, 37, 473-478. [CrossRef] [PubMed]

10. De Waard, D.; Brookhuis, K.A. Assessing driver status: A demonstration experiment on the road. Accid. Anal. Prev. 2001, 23, 297-301. [CrossRef]

11. Fairclough, S.H.; Graham, R. Impairment of driving performance caused by sleep deprivation or alcohol: A comparative study. Hum. Factors 1999, 41, 118-128. [CrossRef] [PubMed]

12. Pack, A.I.; Pack, A.M.; Rodgman, E.; Cucchiara, A.; Dinges, D.F.; Schwab, C.W. Characteristics of crashes attributed to the driver having fallen asleep. Accid. Anal. Prev. 1995, 27, 769-775. [CrossRef]

13. Reyner, L.A.; Horne, J.A. Falling asleep at the wheel: Are drivers aware of prior sleepiness? Int. J. Legal Med. 1998, 111, 120-123. [CrossRef] [PubMed]

14. Arnedt, J.; Wilde, G.; Munt, P.; MacLean, A. Simulated driving performance following prolonged wakefulness and alcohol consumption: Separate and combined contributions to impairment. J. Sleep Res. 2000, 9, 231-233. [CrossRef]

15. Lamond, N.; Dawson, D. Quantifying the performance impairment associated with fatigue. J. Sleep Res. 1999, 8, 255-262. [CrossRef] [PubMed]

16. Williamson, A.; Feyer, A.; Mattick, R.; Friswell, R.; Finlay, S. Developing measures of fatigue using an alcohol comparison to validate the effects of fatigue on performance. Accid. Anal. Prev. 2001, 33, 313-326. [CrossRef]

17. Blanco, M.; Hickman, J.S.; Olson, R.L.; Bocanegra, J.L.; Hanowski, R.J.; Nakata, A.; Greening, M.; Madison, P.; Holbrook, G.T.; Bowman, D. Investigating Critical Incidents, Driver Restart Period, Sleep Quantity, and Crash Countermeasures in Commercial Operations Using Naturalistic Data Collection; Federal Motor Carrier Safety Administration: Washington, DC, USA, 2016.

18. Dingus, T.; Klauer, S.; Neale, V.L.; Petersen, A.; Lee, S.E.; Sudweeks, J.; Perez, M.A.; Hankey, J.; Ramsey, D.; Gupta, S.; et al. The 100-Car Naturalistic Driving Study, Phase II-Results of the 100-Car field experiment (Report No. DOT HS 810 593); National Highway Safety Administration: Washington, DC, USA, 2006.

19. Hanowski, R.J.; Blanco, M.; Nakata, A.; Hickman, J.S.; Schaudt, W.A.; Fumero, M.C.; Olson, R.L.; Jermeland, J.; Greening, M.; Holbrook, G.T.; et al. The Drowsy Driver Warning System Field Operational Test: Data Collection Methods Final Report (Report No DOT HS 810 035); U.S. Department of Transportation: Washington, DC, USA, 2008.

20. Hickman, J.S.; Knipling, R.R.; Olson, R.L.; Fumero, M.C.; Blanco, M.; Hanowski, R.J. Heavy Vehicle-Light Vehicle Interaction Data Collection and Countermeasure Research Project, Phase 1- Preliminary Analysis of Data Collected in the Drowsy Driver Warning System Field Operational Test: Task 5, Preliminary Analysis of Drowsy Driver Warning System Field Operational Test Data; Federal Motor Carrier Safety Administration: Washington, DC, USA, 2016.

21. Olson, R.L.; Hanowski, R.J.; Hickman, J.S.; Bocanegra, J. Driver Distraction in Commercial Vehicle Operations (Report No. FMCSA-RRR-09-042); Federal Motor Carrier Safety Administration: Washington, DC, USA, 2009.

22. Wierwille, W.W.; Ellsworth, L.A. Evaluation of driver drowsiness by trained observers. Accid. Anal. Prev. 1994, 26, 571-581. [CrossRef]

23. Thieriez, K.; Radja, G.; Toth, G. Large Truck Crash Causation Study Interim Report; NHTSA Interim Technical Report \#DOT HS 809 527; National Center for Statistics and Analysis Advanced Research and Analysis: Springfield, VA, USA, 2002.

24. Ferguson, S.; Paech, G.; Sargent, C.; Darwent, D.; Kennaway, D.; Roach, G. The influence of circadian time and sleep dose on subjective fatigue ratings. Accid. Anal. Prev. 2012, 45, 50-54. [CrossRef] [PubMed]

25. Pa Van Dongen, H.; Rogers, N.; Dinges, D. Sleep debt: Theoretical and empirical issues. Sleep Biol. Rhythm. 2003, 1, 5-13. [CrossRef]

26. Czeisler, C.A.; Weitzman, E.D.; Moore-Ede, M.C.; Zimmerman, J.C.; Knauer, R.S. Human sleep: Its duration and organization depend on its circadian phase. Science 1980, 210, 1264-1267. [CrossRef] [PubMed]

27. Dahlgren, K. Adjustment of circadian rhythms and EEG sleep functions to day and night sleep among permanent nightworkers and rotating shiftworkers. Psychophysiology 1981, 18, 381-391. [CrossRef] [PubMed]

(C) 2017 by the authors. Licensee MDPI, Basel, Switzerland. This article is an open access article distributed under the terms and conditions of the Creative Commons Attribution (CC BY) license (http://creativecommons.org/licenses/by/4.0/). 